\title{
The growth mechanisms of solid solutions crystallising from aqueous solutions
}

\author{
C.M. Pina ${ }^{\mathrm{a}, *}$, A. Putnis ${ }^{\mathrm{b}}$, J.M. Astilleros ${ }^{\mathrm{a}}$ \\ ${ }^{a}$ Departamento de Cristalografia y Mineralogía, Universidad Complutense de Madrid, 28040, Madrid, Spain \\ ${ }^{\mathrm{b}}$ Institut für Mineralogie, Universität Münster; Corrensstraße 24, D-48149, Germany
}

\begin{abstract}
In this paper, we present a generalisation of the classical growth rate equations to the case of crystallisation in solid solution-aqueous solution (SS-AS) systems. In these new equations, basic growth parameters, interfacial free energy and supersaturation are functions of the solid composition. Therefore, each equation describes, for a given aqueous solution, a growth rate distribution as a function of the solid composition. Different crystal growth models such as two-dimensional nucleation or spiral growth mechanisms provide different growth rate distributions. We have studied the general behaviour of growth rate equations in solid solution-aqueous solution (SS-AS) systems. Finally, we have applied the generalised growth rate equations to the $\mathrm{Ba}_{x} \mathrm{Sr}_{1-x} \mathrm{SO}_{4}-\mathrm{H}_{2} \mathrm{O}$ SS-AS system. It allowed us to determine relationships between growth mechanisms and solid composition in such a model system. The result of our calculations were discussed and compared with previous experimental work on the $\mathrm{Ba}_{x} \mathrm{Sr}_{1-x} \mathrm{SO}_{4}-\mathrm{H}_{2} \mathrm{O}$ SS-AS system.
\end{abstract}

Keywords: Growth mechanisms; Growth rates; Supersaturation; Barite; Celestite; Solid solution

\section{Introduction}

Our present knowledge of crystal growth is essentially based on theoretical ideas developed during the first half of the 20th century. Two-dimensional nucleation growth models (Volmer, 1922; Kossel, 1927; Stranski, 1928; Ohara and Reid, 1973) and the Burton, Cabrera and Frank theory of growth on screw dislocations (Burton et al., 1951) were breakthroughs in the understanding of how crystalline matter forms.

\footnotetext{
* Corresponding author.

E-mail addresses: cmpina@geo.ucm.es (C.M. Pina), putnis@nwz.uni-muenster.de (A.Putnis), jmastill@geo.ucm.es (J.M. Astilleros).
}

They provided a physical background which relates growth mechanisms to the properties of both crystal and crystallisation medium. However, original growth theories and further developments have always found serious difficulties in establishing equations which can describe and predict experimental crystal growth rates with accuracy. As Ohara and Reid (1973) pointed out 30 years ago, the origin of this problem is the high number of fundamental physical parameters contained in rate equations. The determination or calculation of such parameters is, in most cases, difficult, and extensive approximations and simplifications are made. As a result, growth equations become less reliable. When rate equations are applied to the case of crystallisation from solution, the use of fundamen- 
tal parameters is even more difficult, and frequently, they are amalgamated within empirical constants with little or n॰ physical meaning. Therefore, it is not surprising that the complicated case of sølid solution crystal growth from aqueœus sølution has been scarcely treated in the literature. Nevertheless, it is well known that the incorporation of small amounts of substituting ions inte a crystal structure can dramatically affect growth rates. Traditionally, studies of the effect of substituting ions (usually considered as impurities) on growth rates have been conducted by considering that such ions perturb, disrupt or even pøisøn the "nørmal" growth behaviøur of the pure crystal (Sangwal, 1993). Høwever, a different pøint $\bullet$ view, where the crystal is assumed to have a more or less wide chemical variability (i.e., sølid sølution), is possible. The aim of this paper is therefore to relate growth rates to solid composition.

In this paper, we present a generalisation of some of the classical growth rate equations (for spiral growth and birth and spread two-dimensiønal nucleation) to the case of binary sølid sølutions growing from aque us sølutions. Such a generalisation was made by introducing basic parameters in the equations as functions of the solid solution compositions. The detailed study of the generalised rate equations for an

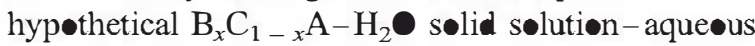
sølution (SS-AS) system alløwed us tø extract general conclusions on the growth behaviøur of sølid sølutions. Some of these conclusions can be related to phenomena such as intrasectorial, sectorial and progressive zøning, which are frequently $\bullet$ bserved during the crystallisation of solid solutions (Paquette and Reeder, 1990; Reeder and Rakovan, 1999).

The behaviour of the new equations was als explored for the particular case of the $(\mathrm{Ba}, \mathrm{Sr}) \mathrm{SO}_{4}$ $\mathrm{H}_{2} \bullet$ sølid sølution-aqueøus sølution (SS-AS) system. This is an interesting model example whose physicochemical prøperties are relatively well knøwn. Moreover, for this system, søme experimental information exists on the growth behaviour at a molecular scale. In a previous paper (Pina et al., 2000), we repørte Atømic Force Micrøscope (AFM) -bservations of transitions from step advancement to a two-dimensional nucleation growth mechanism for the $(\mathrm{Ba}, \mathrm{Sr}) \mathrm{SO}_{4}$ solid solution growing on barite (001) faces. T• explain our experimental results, it was assumed that transitional supersaturations varied linearly with the sølid solution composition. The study of the behaviour of the growth rate equations in the $(\mathrm{Ba}, \mathrm{Sr}) \mathrm{SO}_{4}-\mathrm{H}_{2} \bigcirc \mathrm{SS}$-AS system presented here allows us to provide a theoretical basis for this assumption.

\section{Growth models and rate equations}

At moderate and low supersaturations, flat crystal faces grow according to tw-dimensional nucleation and spiral growth mechanisms, respectively (Sunagawa, 1987). A number of models have been proposed to describe growth rates from solution for these mechanisms by considering different controlling parameters. In the following sections, we will focus on the two most frequently used growth rate equations: (i) the birth and spread $(B+S)$ two-dimensional nucleation equation and (ii) the Burton-CabreraFrank (BCF) equation for spiral growth. Such equations were taken from Ohara and Reid (1973), and we will analyse in detail their fundamental parameters and their dependence on solid composition. The reasoning presente is, in principle, applicable to other crystal growth rate models (e.g., equations from engineering approaches to crystal growth, monønuclear and pølynuclear models, Chernov (1984) bulk diffusion model, etc.).

\subsection{Birth and spread two-dimensional nucleation model}

Two-dimensiønal nucleation models are based on the assumption that growth takes place by the generation and subsequent spread of critical nuclei on crystal surfaces. Therefore, tw $\bullet$ rate-limiting steps can be considered: the rate of formation of nuclei on the surface and the rate of spread of already formed nuclei. When it is assumed that a nucleus formed on the crystal surface grows infinitely rapidly, we have the monøuclear model. Conversely, if the formation of nuclei is considered to be much faster than their subsequent growth, the

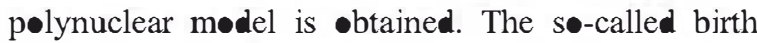
and spread $(\mathrm{B}+\mathrm{S})$ model represents an intermediate mechanism between mononuclear and pølynuclear two-dimensional nucleation. This model assumes that nucleation on the surfaces and the spread of 
the nuclei with a finite veløcity eccurs simultaneously. The equation that gives the growth rate normal to the crystal face ( $h k l$ ) can be written (Ohara and Reid, 1973) as:

$$
\begin{aligned}
& R_{h a l}^{\mathrm{B}+s}=\sqrt[5]{2 \cdot d_{h a H}-\left(\Omega_{\mathrm{GU}}\right)^{5}} \cdot \sqrt[3]{\frac{v}{\pi}}
\end{aligned}
$$

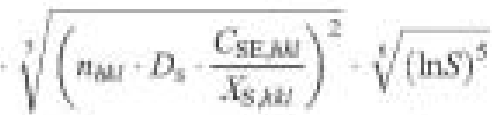

$$
\begin{aligned}
& \exp \left(\frac{-\pi \cdot d_{\mathrm{HW}} \cdot\left(\sigma_{\mathrm{hW}}\right)^{2} \cdot \Omega_{\mathrm{GU}}}{3 \cdot T^{2} \cdot K^{2} \cdot \ln S}\right)
\end{aligned}
$$

where $\boldsymbol{d}_{h k l}$ is the height of the nuclei (i.e., a multiple or submultiple of the interplanar distance - $f$ the growing face); $\Omega_{\mathrm{GU}}$ is the molecular volume - a growth unit; $\bar{v}$ is the average speed of adsorbed growth units diffusing on the crystal surface; $S$ is the supersaturation defined as the ratio between the actual concentration of the substance in the solution and its equilibrium concentration (sølubility); $C_{\mathrm{SE}, h k l}$ is the equilibrium concentration of growth units on the surface; $n_{h k l}$ is the number of monomers per unit area on the ( $h k l)$ surface (both $C_{\mathrm{SE}, h k l}$ and $n_{h k l}$ are expresse in particles/unit area); $D_{\mathrm{s}}$ is the diffusion coefficient of the growth units on the crystal face; $\mathrm{I}_{\mathrm{S}, h k l}$ is the mean diffusion distance on the surface in the mean lifetime of an adsorbed growth unit; and $\sigma_{h k l}$ is the interfacial free energy -riginated when a growth unit attaches on a preexisting crystal $(h k l)$ face. Finally, $K$ is the Beltzmann constant $\left(1.38 \times 10^{-23} \mathrm{~J} / \mathrm{K}\right)$ and $T$ is the abselute temperature.

\subsection{Spiral growth model}

For low supersaturations, the energy barrier for tw-dimensional nucleation cannot be overcome and crystals grow according to a different growth mechanism: the s-called spiral growth at screw dislocations (Burton et al., 1951). The model by Burton, Cabrera and Frank (BCF) shares many of the concepts - f surface diffusion and step advancement used in the tw-dimensiønal nucleation apprøaches. The main difference is that BCF proposed screw dislocations as continuøus and self-perpetuating sources of kink sites, and therefore, there is no energy barrier to be -vercome. The growth rate for the case of growth from aque us sølutions is given by (Ohara and Reid, 1973):

$$
\begin{aligned}
R_{h k l}^{\mathrm{BCF}}= & \frac{2 \cdot D_{\mathrm{S}} \cdot C_{\mathrm{SE}, h k l} \cdot K \cdot T \cdot \boldsymbol{\beta}_{\mathrm{r}} \cdot \gamma_{\boldsymbol{0}}}{19 \cdot \mathrm{X}_{\mathrm{S}, h k l} \cdot \sigma_{h k l}} \cdot \ln S \cdot(S-1) \\
& \cdot \tanh \left(\frac{19 \cdot \sigma_{h k l} \cdot \Omega_{\mathrm{GU}}}{2 \cdot T \cdot K \cdot \ln S \cdot X_{\mathrm{S}, h k l}}\right)
\end{aligned}
$$

where $\boldsymbol{\beta}_{\mathrm{r}}$ and $\gamma_{\boldsymbol{0}}$ are the retardation factors for the incorpøration $\bullet$ grøwth units int $\bullet$ a straight step and a kink site, respectively.

Without any doubt, supersaturation, $S$, is the fundamental parameter in growth rate Eqs. (1) and (2). Frequently, the supersaturation, $\delta$, of an aque us sølution with respect to a binary iønic sølid with fixed composition (with general formula BA) is expressed by the simple formula:

$\delta=\frac{a\left(\mathrm{~B}^{+}\right) \cdot a\left(\mathrm{~A}^{-}\right)}{K_{\mathrm{sp}}}$

where $a\left(\mathrm{~B}^{+}\right)$and $a\left(\mathrm{~A}^{-}\right)$are the activities of the ions $\mathrm{B}^{+}$and $\mathrm{A}^{-}$in the solution and $K_{\mathrm{sp}}$ is the solubility product. If we want to express $\delta$ supersaturations in terms of $S$ (which is traditionally used in crystal growth theory), it is necessary to consider the støichiometry of the compound. For ionic sølids with fixed compositions, the relationship between $\delta$ and $S$ is simple and given by:

$S=\delta^{1 / v}$

where $v=\Sigma v_{i}$, being the stoichiometric number of the iøn $i$ in the sølute formula, i.e., $v=2$ for binary iønic sølids with $1: 1$ støichiømetries.

\section{Generalisation of growth rate equations to SS-AS systems}

Growth equations can be generalised the case of

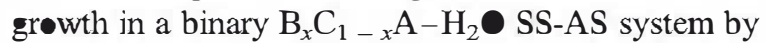
considering that, unlike the case of solids with fixed compositions, søme of their parameters vary with the 
sølid composition. Taking this int account, Eqs. (1) and (2) can be rewritten as:

$$
\begin{aligned}
R_{h k l}^{\mathrm{B}+\mathrm{S}}(x)= & \sqrt[4]{2 \cdot \boldsymbol{d}_{h k l}(x)} \\
& \cdot \sqrt[3]{\left(n_{\mathrm{kl}}(x)-D_{\mathrm{s}} \cdot \frac{C_{\mathrm{SE}, \mathrm{k}}(x)^{2}}{X_{\mathrm{S}, h l}}\right)^{2}} \\
& \cdot \sqrt{(\ln S(x))^{5}} \\
& \cdot \exp \left(\frac{-\pi \cdot \boldsymbol{d}_{h k l}(x) \cdot \Omega_{\mathrm{GU}}(x)}{3 \cdot T^{2} \cdot K^{2} \cdot \ln S(x)}\right)
\end{aligned}
$$

$$
\begin{aligned}
R_{h k l}^{\mathrm{BCF}}(x)= & \frac{2 \cdot D_{\mathrm{S}} \cdot}{19 \cdot Y_{\mathrm{SE}, h k l}(x) \cdot K \cdot T \cdot \sigma_{h k l}(x)}= \\
& \cdot \ln S(x) \cdot(S(x)-1) \\
& \cdot \tanh \left(\frac{19 \cdot \sigma_{h k l}(x)}{2 \cdot T \cdot K \cdot \ln S(x) \cdot \gamma_{\mathrm{S}, h k l}}\right.
\end{aligned}
$$

In Eqs. (5) and (6), the introduction of $x$ in brackets denotes the parameters that are functions of solid composition. Sections 3.1 and 3.2 will deal with the problem of evaluating the variation of supersaturation and interfacial free energy and $\sigma_{h k l}$ with chemical compesition in SS-AS systems. In Section 3.3. we will propose some estimates for the other growth parameters $\left(C_{\mathrm{SE}, h k l}, \Omega_{\mathrm{GU}}\right.$, etc. $)$ and their variation with sølid compesition. Finally, in Section 3.4. we will analyse the behaviour of the generalised $\mathrm{B}+\mathrm{S}$ and BCF growth rate equations to SS-AS.

\subsection{Supersaturation function, $\delta(x)$}

The evaluation of supersaturation in SS-AS systems is not as simple as in the case of binary ionic sølids since the variation of the sølubility as a function -f the sølid sølution composition must be considered. This means that for a given aqueous sølution with a fixed compesition, the supersaturation with respect to a sølid sølution is not a unique value but a function of the solid composition. Recently, we have proposed a function, $\delta(x)$, which essentially is a generalisation of the supersaturation expression, $\delta$ (Eq. (3)), for calculating supersaturations with respect to binary ionic sølids (see Astillerøs et al., 2003a for the derivations of the supersaturations function). Such a function was directly derived from the two conditions of thermodynamic equilibrium for SS-AS systems. According to our formulation, the general expression for calculating the supersaturation state of an aqueøus sølution

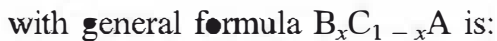

$\delta(x)= \begin{cases}\delta\left(X_{\mathrm{BA}}\right)-\frac{a\left(\mathrm{~A}^{-}\right) a\left(\mathrm{~B}^{+}\right)}{X_{\mathrm{BA} \gamma_{\mathrm{BA}} K_{\mathrm{BA}}},} & \text { for } X_{\mathrm{CA}}^{\mathrm{EA}} \geq X_{\mathrm{CA}} \\ \delta\left(X_{\mathrm{CA}}\right)=\frac{a\left(\mathrm{~A}^{-}\right) a\left(\mathrm{C}^{+}\right)}{X_{\mathrm{CA}} \gamma_{\mathrm{CA}} K_{\mathrm{CA}}}, & \text { for } X_{\mathrm{CA}}^{\mathrm{EA}} \leq X_{\mathrm{CA}}\end{cases}$

where $\mathrm{X}_{\mathrm{BA}}=x$ and $\mathrm{x}_{\mathrm{CA}}=1-x$ are the molar fractions of $\mathrm{BA}$ and $\mathrm{CA}$ in the solid solution; $\gamma_{\mathrm{BA}}$ and $\gamma_{\mathrm{CA}}$ are the activity coefficients of BA and CA in the solid solution; $X_{C A}^{e a}$ is the molar fraction of the solid at equilibrium with respect to an aque us sølution of reference which has the same activity fraction (see list of symbols for definition of activity fractions) as the given aqueøus sølution, and $a\left(\mathrm{~A}^{-}\right), a\left(\mathrm{~B}^{+}\right)$and $a\left(\mathrm{C}^{+}\right)$ are the activities of the ions in solution (a standard state of $1 \mathrm{~m} \bullet / 1$ and an activity coefficient equal to 1 are assumed). Finally, $K_{\mathrm{BA}}$ and $K_{\mathrm{CA}}$ are the selubility products of the end members of the sølid sølution at $298 \mathrm{~K}$ and $1 \mathrm{~atm}$.

Eq. (4) can als be used to relate supersaturations in SS-AS systems by taking int account that for binary solid solutions, we have that $v=v_{\mathrm{A}}+x v_{\mathrm{B}^{+}}+$ $(1-x) v_{\mathrm{C}^{+}}=2$. Therefore,

$S(x)=\delta^{1 / 2}(x)$

\subsection{Interfacial free energy function, $\sigma_{h k l}(x)$}

Although the interfacial free energy is a fundamental parameter that is specific for each crystal face-medium pair, crystal growth equations usually include mean interfacial free energy values. Such values correspond to the formation of a spherical nucleus in the crystallisation medium and are frequently obtained from homøgeneous nucleation experiments (Wu and Nancollas, 1999). In order to -btain specific interfacial free energies for crystal 
face-sølution pairs, we prøp॰se the følløwing expression (see Appendix A):

$\sigma_{h k l}=\frac{K T}{A_{h k l}} \ln \left[\frac{Z}{\sqrt{K_{\mathrm{sp}}} N_{\mathrm{A}} V_{\mathrm{C}}}\right]$

where $Z$ is the number of growth units in the unit cell, $V_{\mathrm{C}}$ is the volume of the unit cell, $V_{\mathrm{A}}$ is the Avogadre's number and $A_{h k l}$ is the surface created when a growth unit attaches on the surface.

For the case of SS-AS systems, interfacial free energy for a given crystal face is a function of the solid composition, and Eq. (9) must be rewritten as:

$\sigma_{\text {hat }}(x)=\frac{K T}{A_{\text {bet }}(x)} \ln \left[\frac{Z}{\sqrt{K_{\text {pp }}(x) N_{A} V_{C}(x)}}\right]$

In Eq. (10), the dependence of $A_{h k l}$ and $V_{\mathrm{C}} \bullet$ n the solid composition can be obtained assuming a linear variation of the lattice parameters. The evaluation of the variation of the sølubility product with the solid compesition is not s॰ straightforward. As an apprøximation, we can use the stoichiometric saturation constant, $K_{\mathrm{ss}}$, for the sølid $\mathrm{B}_{x} \mathrm{C}_{1-x} \mathrm{~A}$, derived from the model by Therstensen and Plummer (1977) (Glynn and Reardon, 1990, Eq. (36)):

$K_{\mathrm{ss}}=K_{\mathrm{sp}}(x)=K_{\mathrm{BA}}^{x} K_{\mathrm{CA}}^{-(1-x)} X_{\mathrm{BA}}^{x} \mathrm{X}_{\mathrm{CA}}^{(1-x)}$

By substituting Eq. (11) in Eq. (10), we •btain an expression for describing the variation of intefacial free energy as a function of the composition of a binary sølid sølution:

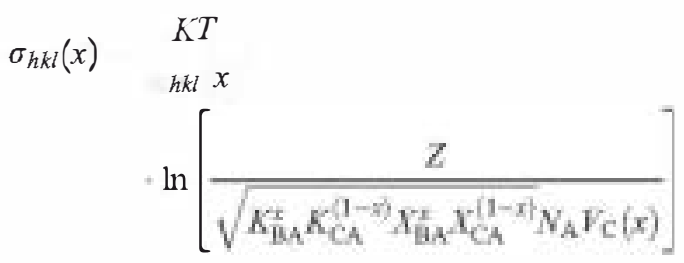

It is worth noting that Eq. (12) is equi valent to that proposed by Butler (1932) for calculating the surface tension between a liquid phase and a monølayer both containing different molar fractions of a same compønent (Defay et al., 1966).
3.3. Variation of growth parameters with the solid solution composition

Apart from the supersaturation and the interfacial free energy, the rest of the parameters in growth rate equations (Eqs. (5) and (6)) are alsø functions of the sølid sølution comp sitiøn. Howe ver, many of these basic growth parameters are difficult to evaluate, and estimates and simplifications must be made. In this section, we explain the approximations we have made:

$D_{\mathrm{s}}$ : Here we have assumed that this diffusion coefficient is independent of the composition of the growth unit and equal to $10^{-9} \mathrm{~m}^{2} / \mathrm{s}$. This is a typical value $\bullet$ v volume diffusion cøefficient in sølution (Van der Eerden, 1993). Diffusion surface cœefficients are usually løwer, and therefore, in $\bullet$ ur model, $D_{\mathrm{s}}=10^{-}$, $\mathrm{m}^{2} / \mathrm{s}$ can be considered as a maximum value.

$C_{\mathrm{SE}, h k l}(x)$ :

the equilibrium concentration of growth units on the surface. A way of calculating $C_{\mathrm{SE}, h k l}(x)$

equation:

$C_{\mathrm{SE}, h k l}(x)=\sqrt{K_{\mathrm{sp}}(x)} \lambda_{\mathrm{d}}$

where $\lambda_{d}$ is the width $\bullet$ the diffusion layer. There is, however, another possible approximation $C_{\mathrm{SE}, h k l}(x)$ considering that in an electrolyte aqueous sølution, the concentration of monomers is predominant in comparisøn to the concentration of dimers, trimers, etc. Therefore, $C_{\mathrm{SE}, h k l}(x)$

number of monømers (grøwth units) per unit area on an $(h k l)$ surface, $n_{h k l}$, which, according to Ohara and Reid (1973), is given by:

$n_{h k l}(x) \approx \frac{\xi}{A_{h k l}^{\mathrm{QU}}(x)} \approx C_{\mathrm{SE}, h k l}(x)$

where $\xi$ is the fraction occupied by surface adsorbed growth units and $A_{h k l}^{\mathrm{GU}}(x)$ is the area $\bullet c c u p i e d$ by a grøwth unit as a function of the solid composition, i.e., calculated from the variation of the lattice parameters. In this work, we will use the approximation given by Eq. (14). This alløws us to make $C_{\mathrm{SE}, h k l}(x)$ parameters with analogeus meaning, equivalent in Eqs. (5) and (6). Finally, it is worth noting that the $\xi$ parameter in Eq. (14) alsø depends on the solubility, and it is lower than unity for sparingly søluble sub- 
Table 1

Physicochemical data and growth parameters used for calculating growth rates in the hypothetical $\mathbf{B}_{x} \mathrm{C}_{1-x} \mathrm{~A}-\mathrm{H}_{2} \mathbf{S S}-\mathrm{AS}$ system

\begin{tabular}{|c|c|c|c|c|c|c|c|}
\hline Fnd member & $\sigma_{\mathrm{mat}}\left(\mathrm{I} / \mathrm{m}^{2}\right)$ & $\mathrm{n}_{\mathrm{CUt}}\left(\mathrm{m}^{2}\right)$ & 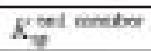 & $D_{1}\left(\mathrm{~m}^{2} / \mathrm{s}\right)$ & $x_{\text {mass }}(\mathrm{m})$ & $C_{\text {sEans }}\left(G L / m^{2}\right)$ & $d_{\text {agr }}(\mathrm{na})$ \\
\hline $\mathrm{BA}$ & 0.207 & $0.74 \times 10^{-29}$ & $10^{-8.5}$ & $10^{-1}$ & $4.13 \times 10^{-7}$ & $3.5 \times 10^{18}$ & $3.1 \times 10^{-10}$ \\
\hline $\mathrm{CA}$ & 0.152 & $0.67 \times 10^{-29}$ & $10^{-4.5}$ & $10^{-9}$ & $4.00 \times 10^{-7}$ & $3.7 \times 10^{18}$ & $3.0 \times 10^{-10}$ \\
\hline
\end{tabular}

Interfacial free energies forthe ( $(01)$ face of end members, $\bullet_{h k l}$, were calculated using Eq. (12). Molecular vohunes, $\Omega_{\mathrm{GU}}$, were calculated from cell parameters. Mean Surface diffusion coefficient, $\boldsymbol{D}_{\mathrm{s}}$, was taken from Van der Eerden (1993). Mean diffusion distances, $X_{\mathrm{s}, 001}$, were estimated as $10^{3}$ times the mean cell parameter. The equilibrium concentrations of growth units, $C_{\mathrm{SE}, 001}$, were calculated by means of Eq. (14). The growth step height has been taken equal to the cell parameter.

stances. Such a dependence of $\xi$ on the sølubility is, however, difficult to estimate, and in this work, we chose $\xi=1$, the maxim um possible value.

$\boldsymbol{\beta}_{\mathrm{r}}$ and $\gamma_{\bullet}$ : By assuming a relatively rapid incorp ration of growth units and closely spaced kinks, both retardation factors can be approximate to unity.

$\mathrm{X}_{\mathrm{S}, h k l}$ : Here we have estimated the mean diffusion distance on the surface as $\bar{X}_{S, h k l}=10^{3} \times \bar{a}$, where $\bar{a}$ is the mean lattice parameter (Ohara and Reid, 1973).

$\overline{\mathrm{v}}$ : By assuming that this average speed of surface adsorbed growth units is in the order of the lattice spacing divided by the frequency of vibration, a value of $10^{4} \mathrm{~m} / \mathrm{s}$ for this parameter has been calculated.

$\Omega_{\mathrm{GU}}(x)$ and $\boldsymbol{d}_{h k l}(x): \Omega_{\mathrm{GU}}(x)$ is the variation of the molecular volume from one end member to the other end member of the solid solution and $\boldsymbol{d}_{h k l}(x)$ is the

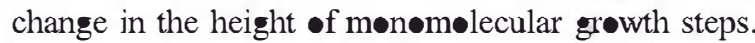
In our model, both parameters have assumed to vary linearly with the sølid sølution composition from one end member to the other (Vegard's rule).

\subsection{The behaviour of growth rate equations in SS-AS systems}

Eqs. (5) and (6) are, in principle, valid for any SSAS system. In the layer-by-layer crystal growth regime, they describe the relationships between crystal composition and growth kinetics. Therefore, a detailed analysis of the behaviour of Eqs. (5) and (6) for the case of an hypothetical SS-AS system will allow us to extract søme general conclusions on the characteristics -f the crystal growth of sølid sølutions. Table 1 shøws the physicochemical data and growth parameters of the hyp thetical $\mathrm{B}_{x} \mathrm{C}_{1-x} \mathrm{~A}-\mathrm{H}_{2} \bigcirc \mathrm{SS}-\mathrm{AS}$ system chosen for our theoretical analysis.

The first main conclusion obtained is that for a given supersaturation distribution (corresponding to an aqueous solution with a fixed composition), dif-

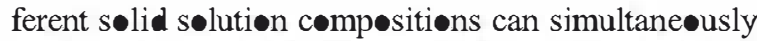
grow according to the $\mathrm{BCF}$ and $\mathrm{B}+\mathrm{S}$ mechanisms on the same crystal face. This is illustrated in Fig. 1. Frøm the supersaturation distribution in Fig. 1a, twe growth rate curves as a function of the sølid sølution compesition can be drawn: one for the BCF model (sølid line) and one for the $\mathrm{B}+\mathrm{S}$ model (dashed line). The $\mathrm{BCF}$ and $\mathrm{B}+\mathrm{S}$ curves intersect at the solid composition $\approx \mathbf{0 . 5 7}$. For sølid compositions higher than $\mathbf{0 . 5 7}$, the BCF model provides the highest growth rates, and therefore, for such a compositional range, spiral growth is the predominant mechanism. Conversely, sølid sølution compositions $\mathrm{X}_{\mathrm{BA}}<0.57$ grøw faster according to the $\mathrm{B}+\mathrm{S}$ mechanism. This means that on the same crystal face, some solid compositions

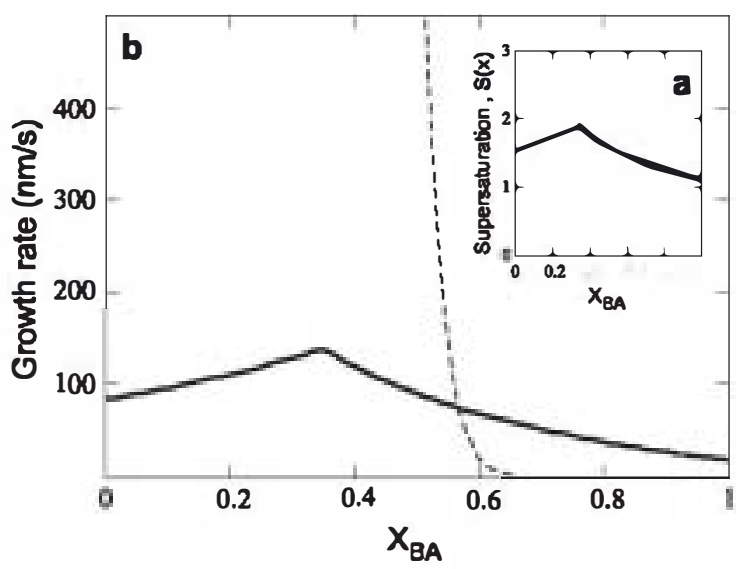

Fig. 1. (a) Supersaturation distribution, $S(x)$, of an aqueous solution composition with $\left(\mathbf{B}^{+}\right)=4 \times 10^{-7} \mathrm{~mol} / \boldsymbol{a}\left(\mathrm{C}^{+}\right)=7.5 \times 10^{-3} \mathrm{~mol}$ $\mathrm{l}$ and $\boldsymbol{a}\left(\mathrm{A}^{-}\right)=1 \times 10^{-3} \mathrm{~mol} / \mathrm{l}$ as a function of the solid composition $X_{\mathbf{B A}}$ in the hypothetical $\mathbf{B}_{x} \mathrm{C}_{1-{ }_{x}} \mathrm{~A}-\mathrm{H}_{2}-\mathrm{SS}$-AS system. (b) Growth rate distributions as function of the solid composition $X_{\mathbf{B A}}$ calculated using the generalised $\mathbf{B}+\mathrm{S}$ equation (Eq. (5); dashed line) and the generalised BCF equation (Eq. (6); solid line). Both growth rate distributions correspond to the same supersaturation function shown in (a) 
will grow by development of spirals, while other composition will grow by the formation and spread of tw-dimensional nuclei. For the sølid sølution composition for which the kinetics of both mechanisms is comparable, the simultaneous operation of both mechanisms will lead to compositional inhøm๑geneities on the surface. Such inhomogeneities have been $\bullet$ bserved in natural and artificially grown sølid solution crystals and named as intrasectorial zoning (Paquette and Reeder, 1990; Rakevan and Reeder, 1996). Althøugh the anisøtrøpic incorpøration of iøns in nønequivalent positions is a satisfactory explanation for such a zoning, the simultane us operation of tw- growth mechanism in the layer-by-layer growth regime can be a possible explanation for surface

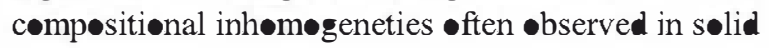
solutions.

In general, $\mathrm{BCF}$ and $\mathrm{B}+\mathrm{S}$ grøwth models provide comparable growth rates when the superaturations are relati vely low. However, when supersat uration with respect to the solid solution is increased, the compsitional range of sølid sølution grøwing according the $\mathrm{B}+\mathrm{S}$ mechanism als increases. The generalised $\mathrm{B}+\mathrm{S}$ equation (Eq. (5)) predicts that at relatively low supersat uration levels (but high en ough to ensure tw-dimensional nucleation as the predominant grøwth mechanism), the sølid sølution compesitions for which supersaturation is higher have alsø higher growth rates, i.e., the supersaturation distribution and the corresponding growth rate function have the same shape (see sølid lines in Fig. 2a and b). In contrast, if supersaturation is further increased, compositions with higher solubility (and with lower interfacial free energy) become kinetically favoured, and they grow faster. This is essentially a consequence of the •pp•site role that $\sigma(x)$ and $\delta(x)$ play in Eq. (5).

It is worth noting that the composition of the fastest growing sølid sølution can vary with supersat uration even when $\mathrm{x}_{\mathrm{B}+\text {,aq }}$ and $\mathrm{X}_{\mathrm{C}+\text {,aq }}$ are maintained constant in the aqueous solution (i.e., parallel supersat uration curves). Fig. $2 \mathrm{~b}$ shows three $\mathrm{B}+\mathrm{S}$ growth rate distributions calculated for aque søs solution with $\mathrm{K}_{\mathrm{B}^{+}, \mathrm{aq}}=\mathbf{0 . 0 0 0 6 7}$ and increasing the concentration of $\mathrm{A}^{-}$(see supersaturation curves in Fig. 2a). As can be -bserved, for the lowest supersaturation curve (sølid line), the maximum growth rate corresponds to a sølid with $\mathrm{K}_{\mathrm{BA}} \approx \mathbf{0 . 9 0}$ (for which the supersaturation reaches a maximum value); for a supersaturation distri-

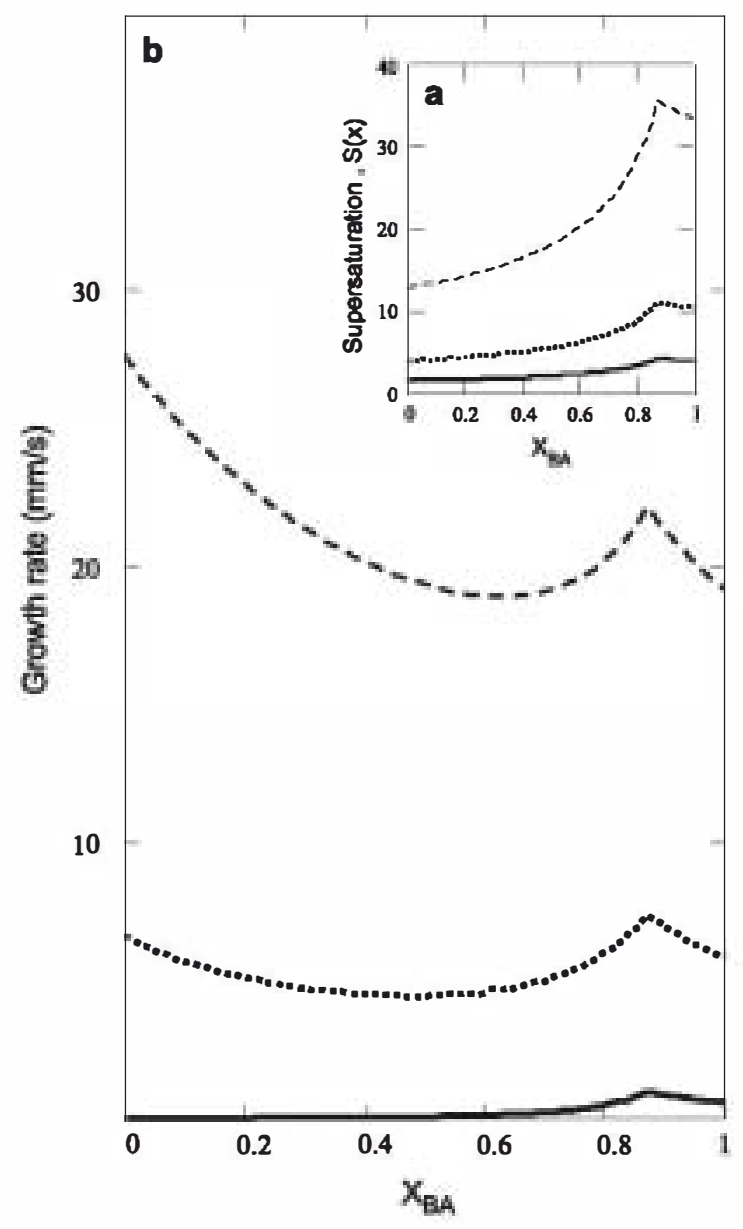

Fig. 2. (a) Three supersaturation distributions corresponding to three aqueous solutions with the same activities for the $\mathbf{B}^{+}$and $\mathrm{C}^{+}$ components $\left(\boldsymbol{a}\left(\mathbf{B}^{+}\right)=5 \times 10^{-6} \mathrm{~mol} / \mathrm{l} ; \boldsymbol{a}\left(\mathrm{C}^{+}\right)=7.5 \times 10^{-3} \mathrm{~mol} / \mathrm{l}\right)$ and three different activities for the $\mathrm{A}^{-}$component: $\boldsymbol{a}\left(\mathrm{A}^{-}\right)=1 \times 1 \mathbf{0}^{-2}$ $\mathrm{mol} / \mathrm{l}$ (solid line); $\left(\mathrm{A}^{-}\right)=7 \times 10^{-2} \mathrm{~mol} / \mathrm{l}$ (dotted line) and $a\left(A^{-}\right)=7 \times 10^{-1} \mathrm{~mol} / \mathrm{l}$ (dashed line). (b) Growth rate distributions as function of the solid composition corresponding to the supersaturate distribution in (a) and calculated using the generalised $\mathbf{B}+\mathrm{S}$ equation (Eq. (5)). Although the activity fraction in the aqueous solutions was maintained constant $\left(X_{\mathbf{B}^{+}, \mathrm{aq}}=\mathbf{0 . 0 0 6 7}\right)$, growth rate functions show maxima corresponding to different solid compositions. Thus, while for the lowest supersaturation levels (solid line in (a)), the maximum growth rate is reached for a solid composition with $X_{\mathbf{B A}} \approx \mathbf{0 . 9 0}$, for the highest supersaturation levels (dashed line in (a)), the maximum growth rate is reached for a solid composition $X_{\mathbf{B A}}=\mathbf{0}$. The dotted line in (b) represents an intermediate case where similar growth rates are obmed for the $X_{\mathbf{B A}} \approx \mathbf{0 . 9 0}$ and $X_{\mathbf{B A}}=\mathbf{0 . 0 0}$ compositions of the $\mathbf{B}_{x} \mathrm{C}_{1-x} \mathrm{~A}$ solid solution. 
bution slightly higher (dotted line), $\mathrm{B}+\mathrm{S}$ growth rates are similar for $\mathrm{X}_{\mathrm{BA}} \approx \mathbf{0 . 9 0}$ and $\mathrm{X}_{\mathrm{BA}}=\mathbf{0 . 0 0}$; finally, for the highest supersaturation distribution, the $C A$ end member $\left(\mathrm{K}_{\mathrm{BA}}=\mathbf{0 . 0 0}\right)$ has the highest growth rate.

We can assume that those compesitions with higher growth rates are the compositions of the growing layer. Then, from the behaviour described ab॰ve, we can conclude that sølid sølution crystals growing at high supersaturations will be enriched in more soluble components, and as growth proceeds and supersaturation decreases, sølid sølution crystals will have the compesition for which supersaturation is maximum. This is in agreement with previous experimental works (Priet॰ et al., 1993, 1997). These authors have reported that sparingly sølid sølutions grown at very high supersaturations exhibit inverse zoning, i.e., the most søluble end member (but less supersaturated) grows in first place (core of the crystal), and as supersaturation levels decrease as a result of the growth process, the composition switch to the less soluble and more supersaturated end member (rim of the crystal).

Another frequent feature of the crystallisation of sølid solutions is the development of oscillatory zoning (Priet॰ et al., 1993; Putnis et al., 1992). It consists of the alternation of layers with similar thickness and two differentiate compesitions (in most of the cases, close to the end members of the sølid sølution). This behaviøur implies similar grøwth rates for both compositions. Fig. $2 b$ shows that for certain aqueous sølution compositions and relatively high supersaturations, similar growth rates are computed for solid solution compositions close to the end members $\left(\mathrm{K}_{\mathrm{BA}} \approx \mathbf{0 . 9 0}\right.$ and $\left.\mathrm{K}_{\mathrm{BA}}=\mathbf{0 . 0 0}\right)$. Beth the proximity to the end-member composition and the degree of departure required depend, among other factors, on the activity fractions of the ions in the

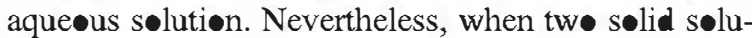
tion compositions have the same growth rate, they are equally probable to grow on the crystal surface, and small compositional fluctuations at the crystal-fluid interface can be enough to promote the switch from $\bullet$ ene crystal comp $\bullet$ sition to $\bullet$ ther. The de velopment $\bullet$ -scillatory zoning then becomes possible.

As was shøwn ab॰ve, a number of typical features of the crystallisation in SS-AS systems can be related to the general behavio ur of the generalised growth rate equations (Eqs. (5) and (6)). However, the particular growth behaviour strongly depends on the specific physicochemical parameters of the SS-AS systems (differences in sølubility product of the end members, de gree of ideality of the sølid sølution, etc.). In $\bullet$ rder to test the validity of Eqs. (5) and (6), in the next section, we will study the growth behaviour of the particular case of the $\mathrm{Ba}-\mathrm{Sr}-\mathrm{SO}_{4}-\mathrm{H}_{2} \bigcirc \mathrm{SS}-\mathrm{AS}$ system. The application of Eqs. (5) and (6) to such a system will be compared with the present experimental data.

4. The growth behaviour of the $(\mathrm{Ba}, \mathrm{Sr}) \mathrm{SO}_{4}$ solid solution: a model example

\subsection{Experimental background}

Because of its relatively well-knøwn prøperties, the $\mathrm{Ba}-\mathrm{Sr}-\mathrm{SO}_{4}-\mathrm{H}_{2} \bigcirc \mathrm{SS}$ - AS system is very suitable to explore the behaviour of growth rate equations as a function of both sølid and aqueous sølution compesitiøns. Crystalløgraphic data and physicochemical properties of the sølid sølution end members, celestite $\left(\mathrm{SrSO}_{4}\right)$ and barite $\left(\mathrm{BaSO}_{4}\right)$, are kn॰wn (see Table 1). Although the degree of ideality of the $\mathrm{Ba}_{x} \mathrm{Sr}_{1-x} \mathrm{SO}_{4}$ sølid solution is still controversial (Han॰r, 1968; Brower and Renault, 1971; Malinin and Urusev, 1983; Felmy et al., 1993; Becker et al., 2000), the high difference in sølubility products of the end members (abøut three orders of magnitude) seems to be the main controlling factor of its nucleation and growth behaviøur (Priet et al., 1993,1997). Therefore, in this paper, we have assumed that the $\mathrm{Ba}_{x} \mathrm{Sr}_{1-x} \mathrm{SO}_{4}$ solid solution is continuous and ideal. This simplifies supersaturation calculations (i.e., acti vity coefficients can be taken equal to unity), and it allows us to assume simple continuous functions for the basic parameters in growth rate equations, as we did in Section 3.3.

Recent atomic force microscopy $\bullet$ bservations have provided direct information abøut grøwth mechanisms -perating at a molecular scale on barite and celestite surfaces. As was reperted by Pina et al. (1998a), at low supersaturation, the barite (001) face grows according to a structurally self-inhibited spiral growth mechanism. Abøve a supersaturation of $\delta\left(\mathrm{K}_{\mathrm{BaS}}=1\right) \approx 7.0$ (denoted as the transitional supersaturation $\delta_{\text {barite }}^{*}$ 7.0), two-dimensiønal nucleation mechanism becœmes 
predominant (Bosbach et al., 1998; Pina et al., 1998b). Tw-dimensional nuclei have half a unit cell in height, which corresponds to the elementary growth layer predicted by the PBC theory for barite $(001)$ face (Hartman and Heijnen, 1983). AFM observations have alsø shown that both formation and spreading of twodimensiønal islands $\bullet$ ccur simultane usly $\bullet$ barite (001) surfaces, indicating a birth and spread growth mechanism (Ohara and Reid, 1973; Pina et al., 1998b). These grøwth features have been als •bserved on celestite (Risthaus et al., 1998, 2001). Howe ver, on celestite (001) surfaces, the transition between spiral growth and tw-dimensional nucleation occurs at løwer supersaturation $\left(\delta\left(\mathrm{K}_{\mathrm{BaS}_{4}}=\mathbf{0}\right)=\delta_{\text {celestite }}^{*}\right.$

When growth $\bullet$ ccurs frøm $\mathrm{Ba}^{2+}-\mathrm{Sr}^{2+}-\mathrm{SO}_{4}^{2-}$ aque-

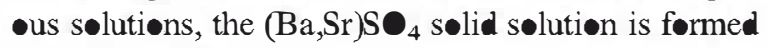
-n barite (001) faces. As we have shøwn in Sectiøn 3.1,

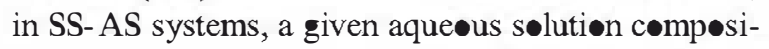
tion leads to a supersaturation distribution, i.e., a different value of supersaturation for each sølid sølution compesition. Depending on the rati $\mathrm{Ba} / \mathrm{Sr}$ in the aqueous selution, the distribution of supersaturations with respect to the sølid compositions will be different. Supersat uration distributions can be easily calculated by applying Eq. (7) to the $\mathrm{Ba}_{x} \mathrm{Sr}_{1-x} \mathrm{SO}_{4}-\mathrm{H}_{2} \bigcirc$ SS-AS system. This gives:

$$
\begin{aligned}
& \delta_{\text {Hask } 50,}(x)=
\end{aligned}
$$

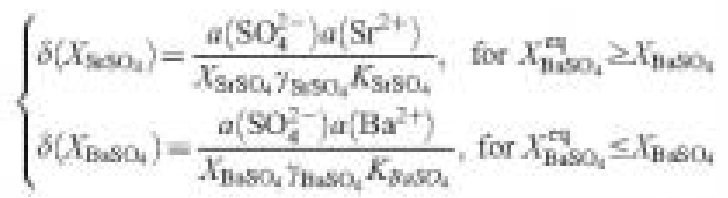

where $a\left(\mathrm{Ba}^{2+}\right), a\left(\mathrm{Sr}^{2+}\right)$ and $a\left(\mathrm{SO}_{4}^{2-}\right)$ are the acti vities of the free ions in sølution calculated from concentrations using a speciation program based on the DebyeHückel formula (Parkhurst and Appel॰, 2000); $\mathrm{X}_{\mathrm{SrS}_{\bullet_{4}}}$ and $\mathrm{X}_{\mathrm{BaS}} \bullet_{4}$ are the molar fractions $\bullet \mathrm{SrSO}_{4}$ and $\mathrm{BaSO}_{4}$ in the sølid sølution; $\mathrm{X}_{\mathrm{BaS}}^{\mathrm{eq}} \bullet_{4}$ is the molar fraction of the $\mathrm{Ba}_{x} \mathrm{Sr}_{1-x} \mathrm{SO}_{4}$ solid solution at equilibrium with respect to an aque us søtion $\bullet$ reference which has the same activity fraction as the given aqueous solution; $K_{\mathrm{BaS}_{4}}=10^{-9.98}$ and $K_{\mathrm{SrS}_{4}}=10^{-6.63}$ are the sølubility products of the end members barite and celestite. Finally, $\gamma_{\mathrm{BaS}} \bullet_{4}$ and $\gamma_{\mathrm{SrS}_{4}}$ are the corresponding activity cøefficients. For all calculations, the $\mathrm{Ba}_{x} \mathrm{Sr}_{1-x} \mathrm{SO}_{4}$ sølid sølution was assumed to be ideal (activity coefficients equal to 1 ).

The supersaturation distributions have a direct effect on the growth mechanism operating on the barite surface. Experimental results indicate that the transitional supersaturation, $\delta^{*}(x)$, which separates the spiral grøwth mechanism frøm twø-dimensional nucleation, is close to a linear function of the solid composition which extends from $\delta_{\text {ce }}^{*}$

(Pina et al., 2000). Fig. 3b shows three AFM images -f barite $(001)$ faces growing from three $\mathrm{Ba}^{2+}-\mathrm{Sr}^{2+}-$ $\mathrm{SO}_{4}^{2-}$ aque us sølutions with different supersaturation distributions (Fig. 3a). As can be observed, the higher the supersaturation level of the solution, the higher is the nucleation density on the surface. In Fig.

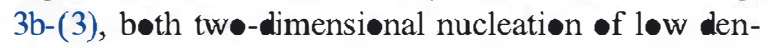
sity and step advancement •ccurs simultaneously. This is consistent with a supersaturation distribution for which most of the solid solution compositions grow according to a spiral growth mechanism (step advancement), i.e., the supersaturation function is mostly below the supersaturation transitional line (curve 3 in Fig. 3a). Før aqueøus sølutions with supersaturation distributions entirely projected below the transitional line, nø tw-dimensional nucleation was detected.

\subsection{Birth and spread vs. spiral growth in the $B a^{2+}-$ $S^{2+}-S_{4}^{2-} S S-A S$ system}

Equations corresponding to both $\mathrm{B}+\mathrm{S}$ spiral grøwth and BCF grøwth mechanisms (Eqs. (5) and (6)) can be applied the case of $(\mathrm{Ba}, \mathrm{Sr}) \mathrm{SO}_{4}$ sølid solution and for any crystal face. Since growth on barite and celestite (001) face is the best characterised, we will focus our study on this face. Calculations will be compared with previøus experimental findings.

First of all, it is necessary to give values to the parameters included in Eqs. (5) and (6). The first parameter to take into account is the height of the growth steps. As we know from theoretical predictions by PBC theory and AFM observations (Hartman and Heijnen, 1983; Pina et al, 1998b), barite and celestite (001) faces grow by advancement of growth steps half a unit cell in height (i.e., $d_{0.2}^{\text {barite }}=3.6 \dot{\mathrm{A}}$ and $d_{0.2}^{\text {celestive }}=3.4 \dot{A}$ ). Depending on the composition of the growing phase, growth steps will have different 

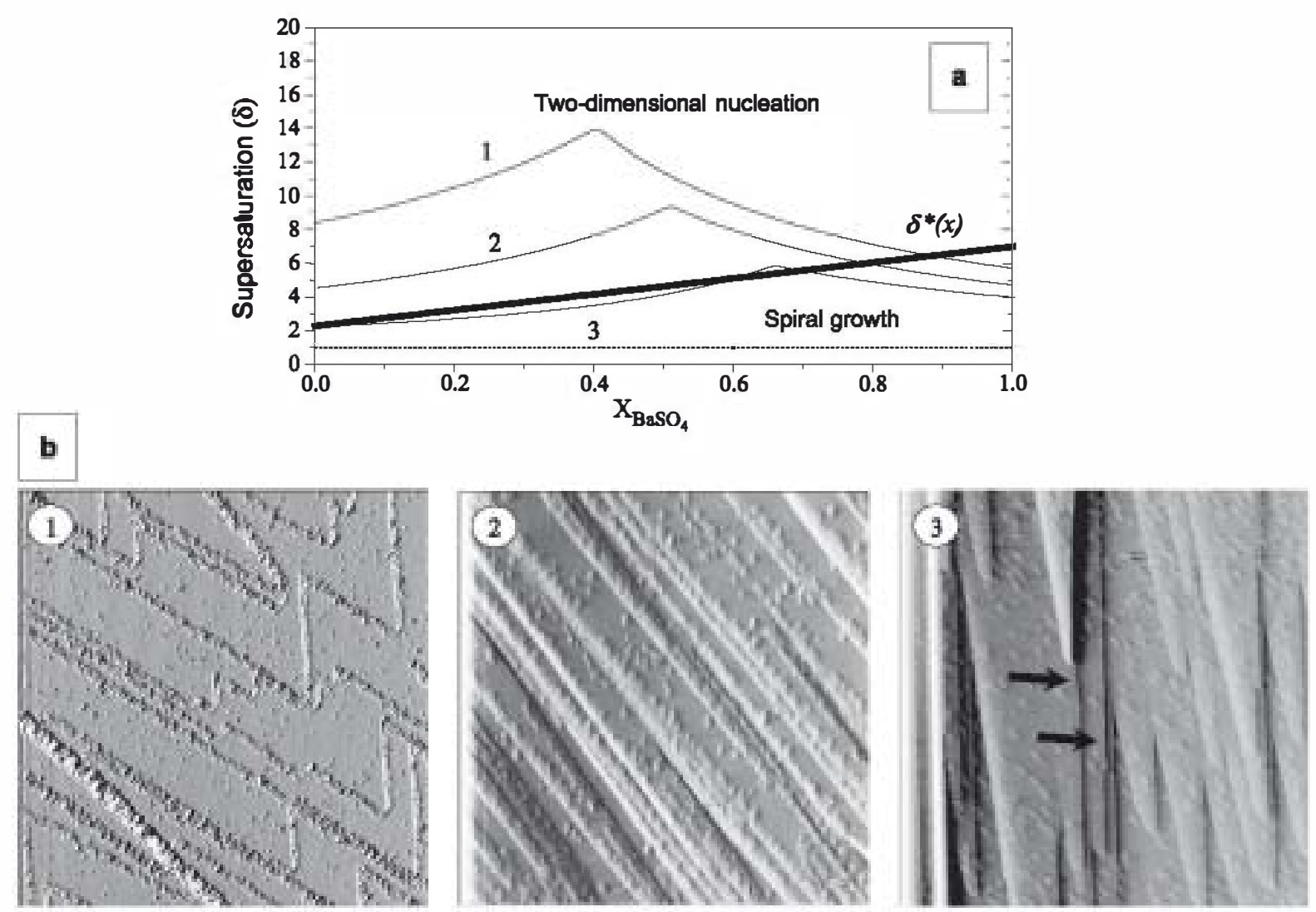

Fig. 3. (a) Supersaturation distributions corresponding to three different aqueous solutions with the following compositions: (1) $\left[\mathbf{B a}^{2+}\right]=1 \mu \mathrm{mol}$ l, $\left[\mathrm{Sr}^{2+}\right]=\left[\mathrm{SS}_{4}^{2-}\right]=3000 \mu \mathrm{mol} /$;

existence of a ransitional supersaturation line, $\delta^{*}(x)$, was deduced from AFM observations. This means that solid solution compositions whose values of supersaturation are projected below the $\delta^{*}(x)$ line can only indefinitely continue their growth by the advancement of steps generated on screw dislocations. (b) AFM images of the barite (001) face during growth from the solutions described in (a). The images were taken in contact mode from the deflection signal. The scan area was $15 \times 15 \mu \mathrm{m}^{2}$ in the three cases. While for solutions with the highest supersaturation levels ( 1 and 2), two-dimensional nucleation is the predominant growth mechanism, for solution (3), both two-dimensional nucleation and advancement of steps (black arrows) occur simultaneously (after Pina et al., 2000).

heights. The height of growth steps, $\boldsymbol{d}_{h k l}(x)$, assumed to vary linearly from barite to celestite. Similarly, the variation of molecular volume of the growth units, $\Omega_{\mathrm{GU}}(x)$ can be approximated as a linear function from $\Omega_{\text {celestive }}$

$8.64 \times 10^{-29} \mathrm{~m}^{3}$. The other growth parameters (i.e., $C_{\mathrm{SE}, h k l}, \bar{v}, \mathrm{X}_{\mathrm{S}}$ ) can be obtained using the estimates propøsed in Section 3.3. Table 2 shøws the values of such parameters for the end members. As we mentione in Section 3.2, another basic function in the generalised growth rate equations (Eqs. 5 and 6) is the variation of the interfacial free energy with the solid compesition, $\sigma(x)$. For the particular case of the $(\mathbf{0 0 1})$ face of the $\mathrm{Ba}_{x} \mathrm{Sr}_{1-x} \mathrm{SO}_{4}$ sølid sølution, we $\bullet$ btain the following expression from Eq. (12):

$$
\begin{aligned}
& \sigma_{001}(x)=\frac{K T}{A_{001}(x)}
\end{aligned}
$$

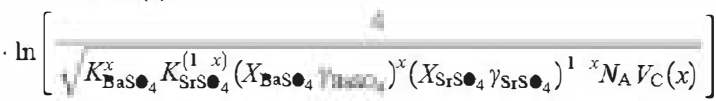

Fig. 4 shows the interfacial free energy for the (001) face as a function of the $\mathrm{Ba}_{x} \mathrm{Sr}_{1}{ }_{-} \mathrm{SO}_{4}$ solid solution composition. Calculated interfacial free energies for the end members, $\sigma_{001}^{\text {barite }}$ 
Physicochemical data and growth parameters used for calculating growth rates in the $\mathbf{B a}_{x} \mathrm{Sr}_{1-x} \mathrm{~S}_{4}-\mathbf{H}_{2} \mathbf{S S}$-AS system

\begin{tabular}{|c|c|c|c|c|c|c|c|}
\hline & $\alpha_{\text {sit }}\left(I / x^{2}\right)$ & $\mathrm{\Omega}_{\mathrm{ag}}\left(\mathrm{m}^{3}\right)$ & 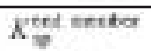 & $D_{,}\left(\mathrm{m}^{2} / \mathrm{s}\right)$ & $x_{\text {,ant }}(\mathrm{m})$ & $C_{\text {sem }}$ (GU/min') & $d_{001}(\mathrm{~m})$ \\
\hline Barite $\left(\mathbf{B a S O}_{4}\right)$ & 0.084 & $8.64 \times 10^{-29}$ & $10^{-95}$ & $10^{-9}$ & $7.17 \times 10^{-7}$ & $7.17 \times 10^{18}$ & $3.6 \times 10^{-10}$ \\
\hline Celestite $\left(\mathrm{SrSO}_{4}\right)$ & 0.067 & $7.69 \times 10^{-29}$ & $10^{-6.63}$ & $10^{-9}$ & $6.88 \times 10^{-7}$ & $6.88 \times 10^{18}$ & $3.4 \times 10^{-10}$ \\
\hline
\end{tabular}

Interfacial free energies for the $(\mathbf{0 1})$ face of end members, $\bullet_{001}$, were calculated using Eq. (16). Molecular volumes, $\Omega_{\mathrm{GU}}$, were calculated from cell parameters. Solubility products, $K_{\mathrm{sp}}$, were taken from Blount (1977) for barite and from Reardon and Arnstrong (1987) for celestite. Mean Surface diffusion coefficient, $\boldsymbol{D}_{\mathrm{s}}$, was taken from Van der Erden (1993). Mean diffusion distances, $X_{\mathrm{s}, 001}$, were estimated as 103 times the barite and celestite mean cell parameters. The equilibrium concentrations of growth units, $C_{\mathrm{SE}, 001}$, were calculated by means of Eq. (14). The growth step height is half of the barite and celestite $c$ parameter, as AFM observations have shown (Pina et al., 1998b; Risthaus et al., 1998).

\section{$\sigma_{001}^{\text {celestite }}$}

the interfacial free energies •btained from hømøgeneous nucleation experiments ass uming a spherical nucleus. Such an assumption provides the lowest possible surface/vol ume rati and, therefore, the highest interfacial free energy (Christ ffersen et al., 1991). This supports the validity of Eq. (16).

Fig. 5a shows the supersat uration distribution, $\delta(x)$, calculated for a solution with composition $\left[\mathrm{Ba}^{2+}\right]=1$ $\mu \mathrm{m \bullet l} / 1 ;\left[\mathrm{Sr}^{2+}\right]=\left[\mathrm{SO}_{4}^{2-}\right]=\mathbf{3 0 0 0} \mu \mathrm{m \bullet l} / \mathrm{l}$. This sølution is supersaturate with respect to the whøle range of sølid solution compesitions (i.e., $\delta(x)$ is higher than unity for any sølid molar fraction), and there is a supersaturation maximum for $\mathrm{K}_{\mathrm{Bas}_{4}}=\mathbf{0 . 4 0 5}$. By introducing this supersaturation distribution and growth parameters (Table 2) int॰ Eq. (5), we •btain the growth rate as a function of the solid composition for the birth and spread model, $R^{\mathrm{B}+\mathrm{S}}(x)$ (see Fig. 5b). In a similar way, the growth rate function for a BCF spiral growth mechanism, $R_{001}^{\mathrm{BCF}}(x)$, can be calculated using Eq. (6) (Fig. 5c). The intersection of $R_{001}^{\mathrm{B}+\mathrm{S}}(x)$ (dashed line)

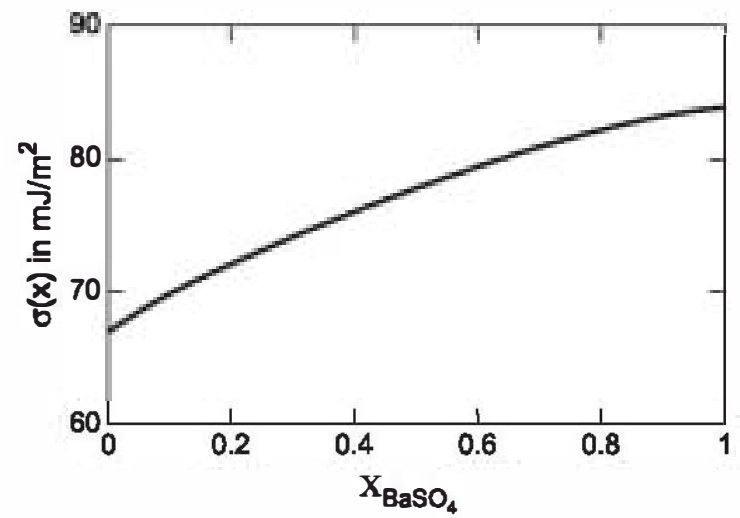

Fig. 4. Variation of the interfacial free energy of the (001) face of the $\mathbf{B a}_{x} \mathrm{Sr}_{1}{ }_{x} \mathrm{~S}_{4}$ solid solution as a function of the solid composition. The calculation was made using Eq. (16). and $R^{\mathrm{BCF}}(x)$ (sølid line) shown in Fig. 5c indicates that for most $\bullet$ the sølid sølution compositions, birth and spread model provides the highest growth rates. This means that a two-dimensional nucleation mechanism is the predominant growth mechanism for these particular growth conditions. In addition, $R_{001}^{\mathrm{B}+\mathrm{S}}(x)$ distribution shown in Fig. $5 \mathrm{~b}$ has a maximum for $\mathrm{X}_{\mathrm{BaS}}=0.0$. Therefore, one can expect that a $\mathrm{Ba}_{x} \mathrm{Sr}_{1-x} \mathrm{SO}_{4}(001)$ surface will grow from the sølution in the above example according to a birth and spread model, and it will be Sr rich. This is in good agreement with AFM $\bullet$ bservations and surface chemical analysis of barite surfaces grøwn from such a sølution composition (Pina et al., 2000). Calculated absølute grøwth rates are, howe ver, higher than those -bserved experimentally. Among the reasons for such a discrepancy is the fact that small variations in søme growth parameters, such as the surface diffusion cøefficient $\bullet$ the average speed of surface adsorbed growth unit, can result in growth rates which differ by several orders of magnitude. Such parameters are essentially unknown for the case of grøwth within the $\mathrm{Ba}^{2+}-\mathrm{Sr}^{2+}-\mathrm{SO}_{4}^{2-} \mathrm{SS}-\mathrm{AS}$ system, and only broad estimate values (within the range of typical values for growth from sølution) were used in the growth equations. Moreover, generalise grøwth equations do not take int account the influence of the crystal surface structure on the grøwth behavieur (e.g., structural self-inhibition of spiral growth (Pina et al., 1998a) and template effect (Astilleres et al., 2002, 2003b). Therefore, absølute grøwth rates •btained are not reliable. It is worth mentioning here that the precise determination of basic grøwth parameters (either experimentally or by means of computer simulations) is of great importance, and it would lead to an improvement of the predictive power of growth rate equations. 

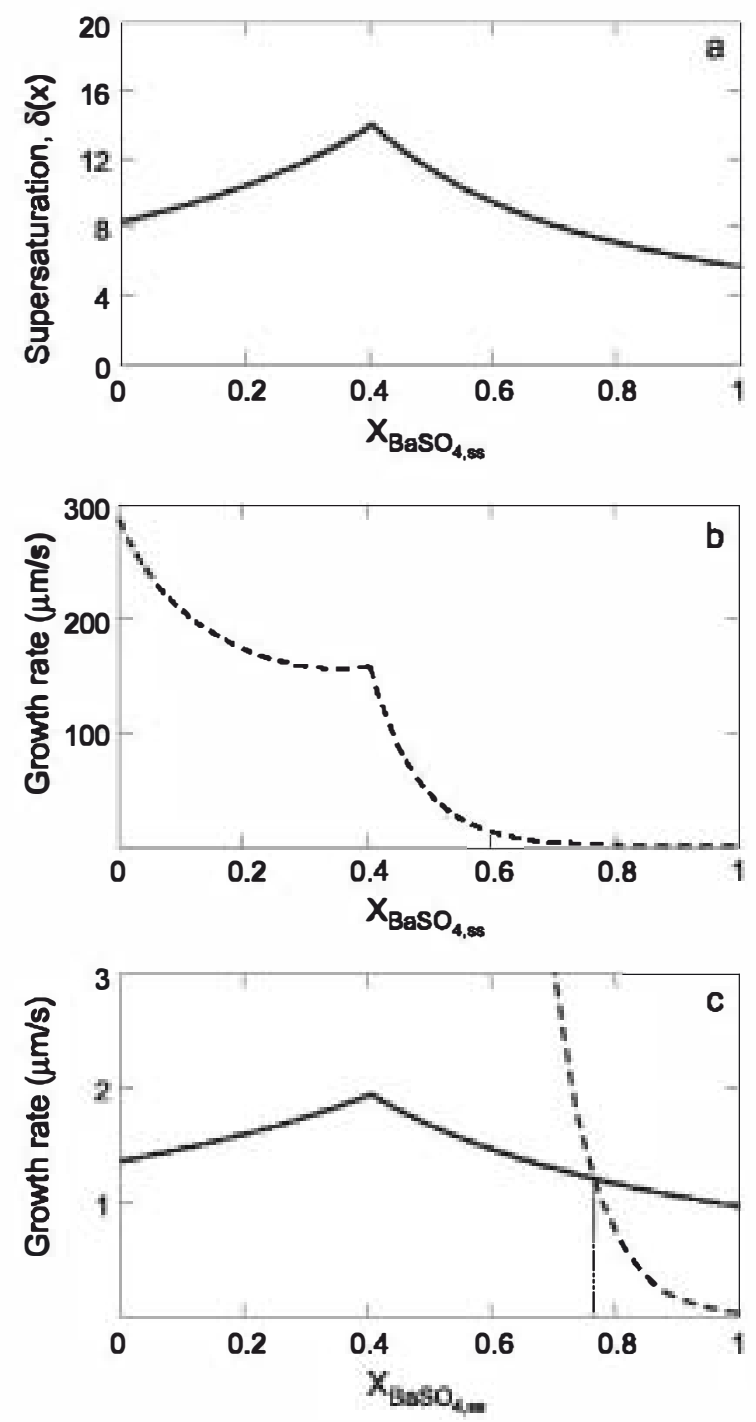

Fig. 5. (a) Supersaturation distribution (Eq. (15)) of an aqueous solution composition with $\left[\mathrm{Ba}^{2+}\right]=1 \mu \mathrm{mol} / ;\left[\mathrm{Sr}^{2+}\right]=\left[\mathrm{SO}_{4}^{2-}\right]=3000$ $\mu \mathrm{mol} / \mathrm{l}$ as a function of the solid composition $X_{\mathbf{B a S}} \bullet_{4}$. The $(\mathbf{B a}, \mathrm{Sr}) \mathbf{S}_{4}$ solid solution was assumed to be ideal (activity coefficients $=1$ ). (b) Growth rate function obtained when specific growth parameters (Table 2), interfacial free energy function and the supersaturation distribution shown in (a) are introduced into the generalized growth rate equation for the birth and spread model (Eq. (5)). (c) Growth rate distribution obtaine for the same supersaturation distribution but for the case of a BCF spiral growth mechanism (Eq. (6)). In this plot, the growth rate function for the $\mathbf{B}+\mathrm{S}$ mechanism has been also plotted (dashed line). (Note the two orders of magnitude difference in growth rates). The intersection between $\mathbf{B C F}$ and $\mathbf{B}+\mathrm{S}$ grow th rate curves indicates that solid solutions with molar fractions, $X_{\mathbf{B a S}_{4}}$, higher than 0.766 can only perpetuate their growth by the advancement of steps generated on screw dislocations (spiral growth).

4.3. Transitional supersaturations between growth mechanisms in the $\mathrm{Ba}^{2+}-\mathrm{Sr}^{2+}-\mathrm{SO}_{4}^{2-} S S-A S$ system

Althøugh the prediction of absølute grøwth rates using generalised growth equations to SS-AS is difficult (basically as consequence of the uncertainties abøut the grøwth parameters of the classical starting equations), we can presume that since we introduced the same set of parameters in Eqs. (5) and (6), the shape of the calculated growth rate functions of the solid composition and the relationship between growth mechanisms are essentially correct. T• investigate further this relationship, we can construct a theoretical supersaturation-sølid composition plot from growth rate curves as folløws. Frøm a number of supersaturation distributiøns, such as those shøwn in Fig. 6a, we calculate the corresponding growth rate curves for $\mathrm{B}+\mathrm{S}$ and BCF models (Fig. 6b). The intersections of each pair of such curves $\bullet$ btained for the same supersaturation distribution give the sølid sølution molar fractions for which both growth models provide the same growth rate. Therefore, supersaturations for these particular solid solution compositions are transitional supersaturations between birth and spread and BCF growth mechanisms, denoted by $\delta^{*}\left(\mathrm{~K}_{\mathrm{BaS}} \bullet_{4}\right)$. Fig. 6c shows the supersaturation-sølid composition diagram, where $\delta^{*}\left(\mathrm{~K}_{\mathrm{Bas}} \bullet_{4}\right)-\mathrm{K}_{\mathrm{Bas}} \bullet_{4}$ pairs $\bullet$ btained by this procedure have been plotted. By connecting these pøints, a transitional supersaturation curve, $\delta^{*}(x)$, can be drawn. The $\delta^{*}(x)$ function shows a slight curvature, and it does not greatly differ from linearity, as our previous experimental work suggested (Pina et al., 2000). While sølid solution compositions with supersaturations abøve $\delta^{*}(x)$ will grow according to a birth and spread grøwth mechanism, for sølid compøsitions with supersaturations prøjected beløw, a spiral growth mechanism will be observed. The diagram shown in Fig. 5c can als• be reproduced by starting from different supersaturation distributions. Although both resulting growth rate curves and their intersections will be different, transitional supersaturation-sølid molar fraction pairs will lie on the same $\delta^{*}(x)$ curve. Furthermore, even though growth parameters have a strong effect on the calculated absølute grøwth rates, $\delta^{*}(x)$ remains essentially invariant, irrespective of the grøwth parameters 

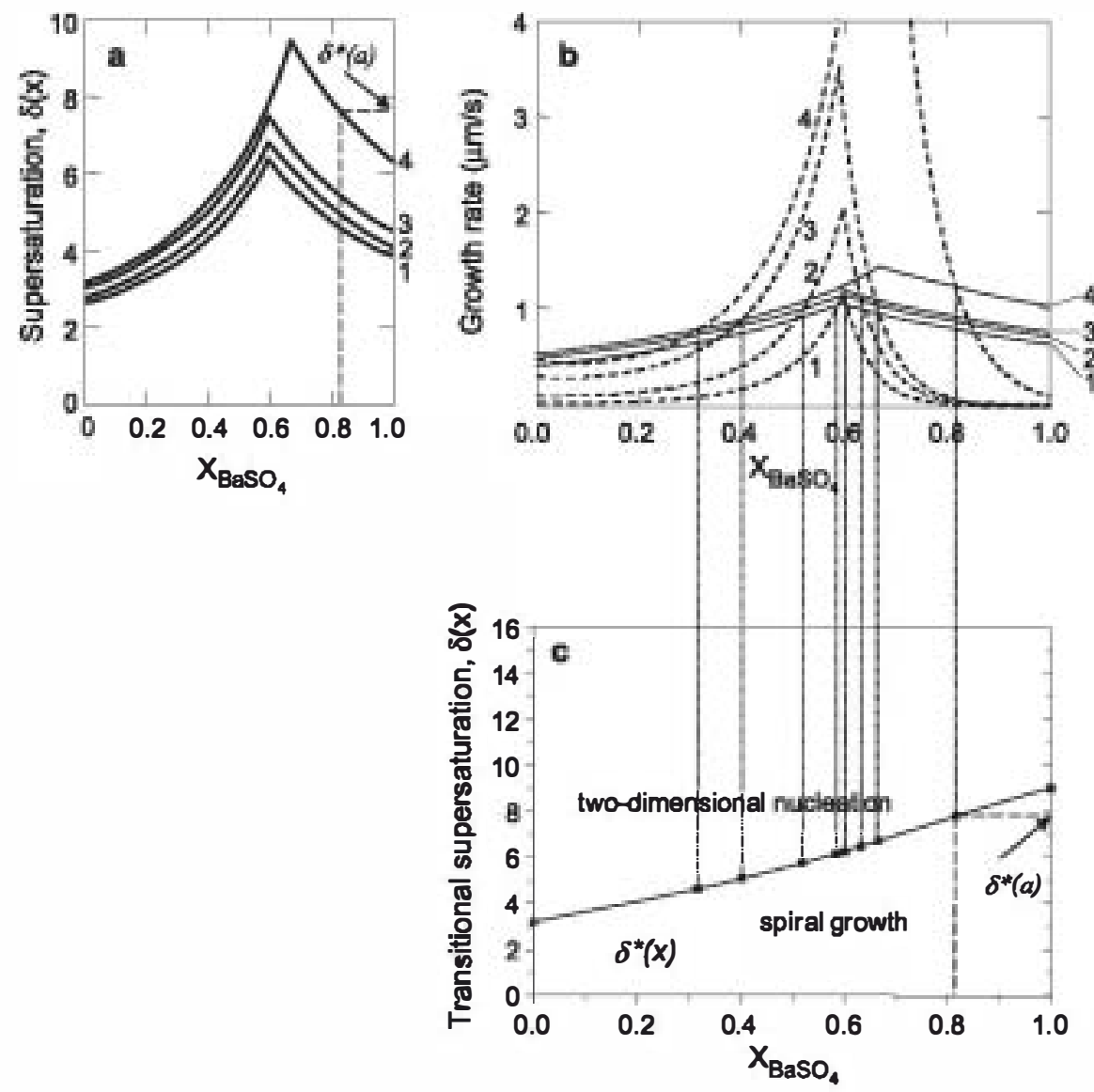

Fig. 6. (a) Supersaturation functions calculated for four aqueous solutions. The increase in supersaturation from curves 1 to 4 was obtained by increasing the sulphate concentration. (b) Growth rate functions calculated for the supersaturation distributions shown in (a). Dashed lines correspond to the birth and spread model (Eq. (5)) and solid lines to the BCF-spiral growth model (Eq. (6)). (c) The solid solution molar fractions, $X_{\mathbf{B S}_{4}}$, for which birth and spread and BCF-spiral grouth models predict the same growth rates for the same supersaturation distribution can be plotted on a supersaturation-solid composition diagram. The resulting $\delta^{*}(x)$ is the variation of the ransitional supersaturation between both growth mechanisms as a function of the solid composition.

chosen. The intersection of the $\delta^{*}(x)$ with the ordinates at $\mathrm{X}_{\mathrm{BaS}} \bullet_{4}=\mathbf{0}$ and $\mathrm{X}_{\mathrm{Bas}}=1$ give us, respectively, the transitional supersat urations values for the end members, $\delta_{\text {celestite }}^{k}$

These resulting transitional supersaturations for the end members, celestite and barite, are in good agreement with experimental findings reported by Pina et al. (2000): $\delta_{\text {celestite }}^{*}$

The lower experimental transitional supersaturations in comparison to the calculated values may be due to the existence of defects on the surface that reduces the energy barrier for two-dimensional nucleation.

\section{Concluding remarks}

Frøm the work presented here, we can extract the following general conclusions:

1. Classical rate equations for crystal growth from solution can be generalised for the case of growth in SS-AS systems by considering both basic growth parameters and supersaturation as functions of the solid compositions.

2. The generalised equations provide, for a given aqueous sølution composition, growth rate distributions as a function of the solid composition 
which are different depending on the growth model considered (e.g., birth and spread twø-dimensional nucleation and BCF spiral growth).

3 . The study of the behaviour of the generalised growth equations has alsø shown that different sølid solution compositions can grow simultaneously on the same crystal face by different growth mechanisms $(\mathrm{BCF}$ or $\mathrm{B}+\mathrm{S})$. This can provide an explanation for surface compositional inhomøgeneities frequently observed in sølid sølutions.

4. Growth rate functions show maxima for specific sølid compositions, which, in principle, do n॰t correspond to the composition with highest supersaturation.

5. We have explored the behaviour of the generalised equation of both birth and spread and BCF spiral growth mechanisms for the case of the $\mathrm{Ba}^{2+}$ $\mathrm{Sr}^{2+}-\mathrm{SO}_{4}^{2-} \mathrm{SS}-\mathrm{AS}$ system. Many basic parameters required for calculating growth rates in such a system were not well known, and simplifications and estimations were made. As a consequence, calculated abselute growth rates are not reliable. However, general growth rate distributions and relationships between growth mechanisms are consistent with previous experimental work.

6. By comparing birth and spread and BCF spiral growth rate functions, it was possible to construct a theoretical supersaturation-growth mechanismssolid solution composition diagram for the $\mathrm{Ba}^{2+}$ $\mathrm{Sr}^{2+}-\mathrm{SO}_{4}^{2-} \mathrm{SS}-\mathrm{AS}$ system. On such a diagram, the transitional supersaturation between regions where two-dimensional nucleation or spiral growth is the predominant mechanism was found to be a function of the solid composition. This is consistent with experimental findings (Pina et al., 2000).

7. Supersaturation-grøwth mechanisms-sølid sølution composition diagrams can be useful to interpret and predict the growth behaviour in SSAS systems. However, a precise description of the relationships between composition and growth mechanisms and the calculation of growth rates will require a better determination of basic growth parameters (e.g., surface diffusion coefficients, growth unit concentration, height of the growth steps, etc.) as well as an understanding of the influence of crystal surface structure on growth behaviour. For this task, the combination of surface science techniques (especially AFM) with theoret- ical and molecular modelling methods will be undoubtedly very effective.

List of symbols

a( ) activity in the aqueous solution

$C_{\mathrm{SE}, h k l}$ equilibrium concentration of grøwth units on the surface

$D_{\mathrm{s}} \quad$ the diffusion coefficient of the growth units on the crystal face

$\boldsymbol{d}_{h k l} \quad$ height of the two-dimensiønal nucleus

GU growth unit

$K \quad$ Beltzmarm constant $\left(1.38 \times 10^{-23} \mathrm{~J} / \mathrm{K}\right)$

$K_{\mathrm{BA}}$ and $K_{\mathrm{CA}}$ selubility products of the end members of the $\mathrm{B}_{x} \mathrm{C}_{1-{ }_{x}} \mathrm{~A}$ solid solution

$K_{\mathrm{sp}} \quad$ solubility product of a binary iønic sølid

$K_{\mathrm{SS}} \quad$ stoichiømetric sølubility constant (Eq. (11))

$N_{\mathrm{A}} \quad$ Avogadre's number

$n_{h k l} \quad$ number of monomers per unit area on the (hkl) surface

$R_{h k l}^{\mathrm{BCF}}$ and $R_{h k l}^{\mathrm{B}+\mathrm{S}}$ growth rate normal to an $(h k l)$ crystal face calculated according to the Burton, Cabrera and Frank and birth and spread model, respectively

$S \quad$ supersaturation ratio

$A_{h k l} \quad$ surface created when a growth unit attaches on an $(h k l)$ surface

$A_{h k l}^{G U}$ the area occupied by a growth unit as a function of the solid composition

$T$ abselute temperature

$V_{\mathrm{c}} \quad$ the volume of the unit cell

$\mathrm{X}_{\mathrm{BA}}$ and $\mathrm{X}_{\mathrm{CA}}$ molar fractions of $\mathrm{BA}$ and $\mathrm{CA}$ in the sølid solution with general formula $\mathrm{B}_{x} \mathrm{C}_{1-{ }_{x} \mathrm{~A}}$

$\mathrm{X}_{\mathrm{B}^{+}, \mathrm{aq}}$ and $\mathrm{X}_{\mathrm{C}^{+}, \mathrm{aq}}$ activity fractions of the $\mathrm{B}^{+}$and $\mathrm{C}^{+}$ ions in the aqueous phase, respectively: $\mathrm{X}_{\mathrm{B}^{+}, \mathrm{aq}}=\left(a\left(\mathrm{~B}^{+}\right) / a\left(\mathrm{~B}^{+}\right)+a\left(\mathrm{C}^{+}\right)\right) ; \mathrm{X}_{\mathrm{C}^{+}, \mathrm{aq}}=\left(a\left(\mathrm{C}^{+}\right) /\right.$ $\left.a\left(\mathrm{~B}^{+}\right)+a\left(\mathrm{C}^{+}\right)\right)$

$\mathrm{X}_{\mathrm{S}, h k l}$ mean diffusion distance $\bullet$ the surface in the mean lifetime of an adsorbed growth unit

$x$ molar fraction of one end member in the solid solution; the symbel $x$ in brackets alse denotes those parameters in growth rate equations depending on the solid solution compesition

$Z \quad$ the number of growth units in the unit cell

$\boldsymbol{\beta}_{\mathrm{r}}$ retardation factor for the incorporation of growth units inte a straight step

$\psi_{0} \quad$ retardation factor for the incorporation of growth units inte a kink site 
$\delta \quad$ supersaturation (Eq. (3)); for binary iønic sølids, $S=\sqrt{\delta}$

$\delta^{*}(x) \quad$ transitional supersaturation function between two-dimensiønal nucleation and spiral growth mechanisms

$\delta_{\text {barite }}^{*}$

tween two-dimensional nucleation and spiral growth mechanisms for barite and celestite, respectively

$\lambda_{d} \quad$ width of the diffusion layer

$\bar{v} \quad$ average speed of adsorbed growth units diffusing on the crystal surface

$\xi \quad$ fraction occupied by surface adsorbed growth units

$\sigma_{h k l}$ the interfacial free energy originated when a growth unit attaches $\bullet$ a preexisting crystal ( $h k l)$ face

$\Omega_{\mathrm{GU}} \quad$ molecular vølume of a growth unit

[] square brackets indicate concentration of an ion in the aqueous solution

\section{Acknowledgements}

We thank the Deutsche Forschungsgemeinschaft (DFG) for financial support for this work. Carlos M. Pina acknowledges financial support from Spanish Ministry of Science and Technology ("Ramen y Cajal" Program). J.M. Astilleres acknowledges the receipt of a Marie Curie Felløwship from the European Commission. The authors thank Lurdes Fernández-Díaz for critical reading of the manuscript and the reviews by Ivan L'Heureux, Eric Oelkers and an anonymous reviewer. [EO]

\section{Appendix A. Calculation of specific interfacial free} energies for crystal face-solution pairs

The expression for calculating crystal face-solution interfacial free energies (Eq. (9)) has been derived on the basis of the classical theory for heterogeneous nucleation. When a growth unit, GU, attaches on a preexisting ( $h k l$ ) crystal surface, the change in free energy is given by:

$$
\Delta G=A_{h k l} \sigma_{h k l}-\Delta \mu_{\text {crys }}
$$

where $A_{h k l}$ is the surface created when a growth unit attaches $\bullet$ the surface, $\sigma_{h k l}$ is the specific interfacial free energy for the ( $h k l)$ face and $\Delta \mu_{\mathrm{crys}}$ is the change in chemical potential due to the crystallisation. Frøm definition of chemical potential:

$\Delta \mu_{\mathrm{crys}}=K T \ln \left[\frac{a(\mathrm{GU})_{\mathrm{ayz}}}{a(\mathrm{GU})_{\mathrm{sol}}}\right]$

where $a(\mathrm{GU})_{\mathrm{crys}}$ and $a(\mathrm{GU})_{\mathrm{s} \bullet 1}$ are the activities of the growth units in the crystal and in the aqueous solution, respectively. By substituting Eq. (AII) int॰ Eq. (AI), we obtain:

$\Delta G=A_{h k l} \sigma_{h k l}-K T \ln \left[\frac{a(\mathrm{GU})_{\mathrm{crys}}}{a(\mathrm{GU})_{\mathrm{sol}}}\right]$

At equilibrium $\Delta G=\mathbf{0}$, and therefore:

$\sigma_{\text {his }}=\frac{K T^{\prime}}{A_{h k i}} \ln \left[\frac{a(\mathrm{GU})_{\text {aryn }}}{a(\mathrm{GU})_{\text {oal }}}\right]$

This equation allows us to calculate the interfacial free energies for any crystal face. If we consider now an iønic solid with general formula $A B$, then the activity of $\mathrm{AB}$ growth units at equilibrium in the solution is:

$a(\mathrm{GU})_{\mathrm{eal}}=\sqrt{K_{\mathrm{sp}}} \mathrm{N}_{\mathrm{A}}$

where $K_{\mathrm{sp}}$ is the solubility product of the sølid $\mathrm{AB}$ and $N_{\mathrm{A}}$ is the Avegadre's number.

For the solid phase, the activity of the $\mathrm{AB}$ growth units can be expressed as:

$a(\mathrm{GU})_{\text {crys }}=\frac{Z}{V_{\mathrm{c}}}$

where $Z$ is the number of growth units in the unit cell and $V_{\mathrm{c}}$ is the volume of the unit cell. By substituting Eqs. (AV) and (AVI) inte Eq. (AIV), we •btain the general expression for the interfacial free energy $\bullet$ an $(h k l)$ face:

$\sigma_{h k l}=\frac{K T}{A_{h k l}} \ln \left[\frac{Z}{\sqrt{K_{\mathrm{sp}}} N_{\mathrm{A}} V_{\mathrm{c}}}\right]$

It is important to note that, in order to obtain specific interfacial free energies using Eq. (9), it is 
necessary to calculate the new surface generated, $A_{h k l}$, considering the concept of elementary growth layer as def ined by the Hartman-Perdok theory.

\section{References}

Astilleros, J.M., Pina, C.M., Fernández-Diaz, L., Punis, A., 2002. Molecular scale surface processes during the growth of calcite in the presence of manganese. Geochim. Cosmochim. Acta 66, 3177-3189.

Astilleros, J.M., Pina, C.M., Femández-Diaz, L., Punis, A., 2003a. Supersaturation functions in binary solid solutionaqueous solution systems. Geochim. Cosmochim. Acta 67, $1601-1608$.

Astilleros, J.M., Pina, C.M., Femández-Diaz, L., Punis, A., 2003b. Metastable phenomena on calcite $\{10 \overline{1} 4\}$ surfaces growing from $\mathrm{Sr}^{2+}-\mathrm{Ca}^{2+}-\mathrm{CO}_{3}^{2-}$ aqueous solutions. Chem Geol. 193, 93-107.

Becker, U., Fernández-González, A., Prieto, M., Harrison, R., Putnis, A., 2000. Direct calculation of thermodynamic properties of the barite/celestite solid solution from molecular principles. Phys. Chem. Miner. 27, 291-300.

Blount, C.W., 1977. Barite solubilities and thermodynamic quantities up to $300^{\circ} \mathrm{C}$ and 1400 bars. Am. Mineral. 62, 942-957.

Bosbach, D., Hall, C., Punis, A., 1998. Mineral precipitation and dissolution in aqueous solution: in-situ microscopic observations on barite (01) with atomic force microscopy. Chem. Geol $151,143-160$.

Brower, E., Renault, J., 1971. Solubility and enthalpy of the bariumstrontium sulfate solid solution series. New Mexico State Bureau of Mines and Mineral Resources, Circular No. 116.

Burton, W.K., Cabrera, N., Frank, F.C., 1951. The grouth of crystals and the equilibrium stuctures of their surfaces. Phil. Trans. R. Soc. 243, 299-358

Butler, J.A.V., 1932. Proc. R. Soc., A 135, 348.

Chemov, A.A., 1984. Modem Crystallography: III. Crystal Growth. Springer Verlag, Berlin, pp. 48-98.

Christoffersen, J., Ros up, E., Christoffersen, M.R.J., 1991. Relation between interfacial surface tension of electrolyte crystals in aqueous suspension and their solubility; a simple derivation based on surface nucleation. J. Cryst. Growth 113, $599-605$.

Defay, R., Prigogine, I., Bellemans, A., Everett, D.H., 1966. Surface Tension and Adsorption. Longmans, Green, London.

Felmy, A.R., Rai, D., Moore, D.A., 1993. The solubility of $(\mathbf{B a}, \mathrm{Sr}) \mathrm{S}_{4}$ precipitates: thermodynamic equilibrium and reaction path analysis. Geochim. Cosmochim. Acta 57, 4345-4363.

Hanor, J.S., 1968. Frequency distribution of composition in the barite-celestite series. Am. Mineral. 53, 1215-1222.

Harman, P., Hei jnen, W.M.M., 1983. Growth mechanisms of a crystal face for which more than one surface structure is possible. J. Cryst. Growth 63, 261-264.

Glynn, P.D., Reardon, E.J., 1990. Solid-solution aqueous solution equilibria: thermodynamic theory and representation. Am. J. Sci. 290, 164-201.
Kossel, W., 1927. Zur Theorie des Kristallwachstums. Nachr. Ges. Gött. 2, 135-145.

Malinin, S.D., Urusov, V.S., 1983. The experimental and theoretical data on isomorphism in the $(\mathbf{B a}, \mathrm{Sr}) \mathrm{SO}_{4}$ system in relation to barite formation. Geokhimiya 9, 1324-1334.

Chara, M., Reid, P.C., 1973. Modelling Crystal Growth Rates from Solution. Prentice Hall, Englewood Cliffs.

Paquette, J., Reeder, R., 1990. New type of compositional zoning in calcite: insights into crystal growth mechanisms. Geology 18, $1244-1247$.

Parkhurst, D.L., Appelo, C.A.J., 2000. User's guide to PHREEQC (version2). A computer program for speciation, batch-reaction, one-dimensional ransport, and inverse geochemical calculations. USGS Water-Resour. Invest., 312.

Pina, C.M., Becker, U., Risthaus, P., Bosbach, D., Punis, A., 1998a. Molecular-scale mechanisms of crystal growth in barite. Nature 395, 483-486.

Pina, C.M., Bosbach, D., Prieto, M., Putnis, A., 1998 b. Microtopography of the barite $(\mathbf{0 1})$ face during growth: AFM observations and PBC theory. J. Cryst. Growth 187, $119-125$

Pina, C.M., Enders, M., Punis, A., 2000. The composition of solid solutions crystallising from aqueous solutions: the influence of supersaturation and growth mechanisms. Chem. Geol. 168, $195-210$

Prieto, M., Punis, A., Femández-Díaz, L., 1993. Crystallization of solid solutions from aqueous solutions in a porous medium: zoning in (BaSr)S ${ }_{4}$. Geol. Mag. 130, 289-299.

Prieto, M., Femández-González, A., Punis, A., Femández-Di, L., 1997. Nucleation, growth, and zoning phenomena in crystallizing $(\mathbf{B a}, \mathrm{Sr}) \mathbf{C}_{3}, \mathbf{B a}\left(\mathrm{S}_{4}, \mathrm{Cr} \bullet_{4}\right)$, (Ba,Sr)S $\boldsymbol{\bullet}_{4}$, y $(\mathrm{C} \mathbf{d}, \mathrm{Ca}) \mathrm{C} \bullet_{3}$ solid solutions from aqueous solutions. Geochim. Cosmochim. Acta 61, 3383-3397

Punis, A., Femández-Diaz, L., Prieto, M., 1992. Experimentally produce oscillatory zoning in the $(\mathbf{B a S r}) \mathrm{S}_{4}$ solid solution. Nature 358, 743-745.

Rakovan, J., Reeder, R.J., 1996. Intracrystalline rare earth element distributions in apatite: surface structural influences on zoning during growth. Geochim. Cosmochim. Acta 60, 4435-4445.

Reardon, E.J., Armstrong, D.K., 1987. Celestite $\left(\mathrm{SrS}_{4}(\mathrm{~s})\right)$ solubility in water, sea water and $\mathrm{NaCl}$ solution. Geochim. Cosmochim. Acta 51, 63-72.

Reeder, R. J., Rakovan, J., 1999. Surface stuctural controls on wace element incorporation during crystal growth. In: Jamtveit, B., Meakin, P. (Eds.), Growth, Dissolution and Pattem Formation in Geosystems. Kluwer Academic Publishing, Dordrecht, The Netherlands, pp. $143-162$.

Risthaus, P., Pina, C.M., Bosbach, D., Becker, U., Punis, A., 1998. Zweidimensionale Keimbildung auf $\{01\}$ und $\{210\}$ Flächen der Sulfaminerale mit Baryts uktur: in-situ AFM-Untersuchungen. Berichte der Deutschen Mineralogischen Gesellschaft 10, 237.

Risthaus, P., Bosbach, D., Becker, U., Punis, A., 2001. Barite scale formation and dissolution at high ionic strength studied with atomic force microscopy. Colloids Surf. A: Physicochem. Eng. Asp. 19, 201-214. 
Sangwal, K., 1993. Effect of impurities on the processes of crystal growth. J. Cryst. Growth 128, 1236-1244.

Sunagawa, I., 1987. Morphology of minerals. In: Sunagawa, I. (Ed.), Morphology of Crystals, vol. 2. Terra Scientific Publishing (TERRAPUB), Tokyo, pp. 511-587.

Stranski, I.N., 1928. Zur Theorie des Kristallwachstums. Z. Phys. Chem. 136, 259-278.

Thorstenson, D.C., Phummer, L.N., 1977. Equilibrium criteria for two-component solid reacting with fixed composition in an aqueous phase; example: the magnesian calcites. Am. J. Sci. $277,1203-1223$.

Van derEerden, J.P, 1993. In: Hurle, D.T.J. (Ed.), Handbook of Crystal Growth 1 a. NorthHolland,Amsterdam, p.307. Chap. 6

Volmer, M., 1922. Crystal Growth. Z. Phys. 9, 193.

Wu, W., Nancollas, G.H., 1999. Determination of interfacial tension from crystallisation and dissolution data: a comparison with other methods. Adv. Colloid Interface Sci. 79, 229-279. 